\title{
How to Dissect Lymphatics under Loupes for Line Production System for Multiple Lymphaticovenular Anastomosis
}

\author{
Tarek Elsayed Mohamed Eldahshoury, MRCS, MS ${ }^{1}$ Shuhei Yoshida, MD, PhD ${ }^{1}$ Isao Koshima, MD, PhD ${ }^{1}$ \\ Hirofumi Imai, MD ${ }^{1}$ Toshio Uchiki, MD² Ayano Sasaki, MD ${ }^{2}$ Shogo Nagamatsu, MD, PhD ${ }^{2}$ \\ Kazunori Yokota, MD, $\mathrm{PhD}^{2}$

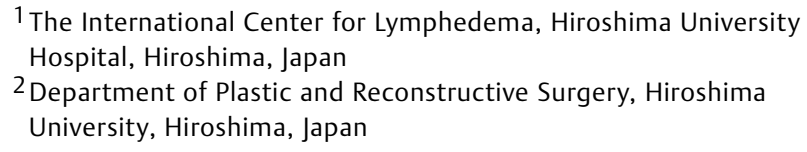

${ }^{1}$ The International Center for Lymphedema, Hiroshima University

2 Department of Plastic and Reconstructive Surgery, Hiroshima \\ Address for correspondence Shuhei Yoshida, MD, PhD, The \\ International Center for Lymphedema, Hiroshima University Hospital, \\ 1-2-3, Kasumi, Minami-ku, Hiroshima 734-8551, Japan \\ (e-mail: syuheiyoshida44@gmail.com).
}

J Reconstr Microsurg Open 2020;5:e43-e48.

\begin{abstract}
Keywords

- lymphatics

- dissection

- loupes

Background A surgical line production system using loupes to dissect lymphatics and veins is a cost-effective way of performing multiple lymphaticovenular anastomoses. There is an art to successful dissection of lymphatics under loupes, and selection of the correct loupe magnification is important. Therefore, the aim of this study was to provide a detailed description of how to dissect lymphatics under loupes.

Patients and Methods Dissection of lymphatics under loupes was performed for a series of 13 patients. Lymphatics are transparent threadlike structures that are arranged longitudinally and may be oriented with feeding capillary vessels. At the start of dissection, it is helpful to have a reference scale in the field of vision when operating to appreciate the size of the structures seen under loupes. It is also helpful to be able to separate lymphatics from fat tissue in the background.

Results Mean time for exploration under loupes was $25 \pm 7$ minutes; lymphatics were successfully found in 27 sites (90\%) of the 30 attempted with failure to identify lymphatics in three sites $(10 \%)$ and failure to identify veins in three sites (10\%); the average size of the lymphatics was found to be $0.5 \pm 0.2 \mathrm{~mm}$. No lymphatics could be found by the microscopes after loupes exploration in two sites.

Discussion Even a novice surgeon can identify lymphatics based on knowledge of the visual characteristics of these structures. However, a higher magnification is likely necessary for accurate discrimination.
\end{abstract}

In some patients with lymphedema, it is important to create as many lymphaticovenular anastomoses (LVAs) as possible. ${ }^{1}$ In such cases, LVAs are usually performed simultaneously at multiple sites and require use of at least two operating microscopes. ${ }^{2}$ A drawback of this method is that it requires more than two expert microsurgeons, each equipped with an operating microscope, which is beyond the resources of many hospitals. This problem can be overcome by imple- menting a line production system (LPS) whereby multiple LVAs can be performed using loupes for dissection of lymphatics and veins. ${ }^{3}$ Dissection of lymphatics under loupes is feasible for a novice surgeon; however, it is necessary to master some "tricks of the trade" to be able to find and dissect lymphatics under loupes efficiently. The aim of this paper was to describe in detail how to dissect lymphatics accurately under loupes. received

April 5, 2020

accepted

May 28, 2020
DOI https://doi.org/

10.1055/s-0040-1714660. ISSN 2377-0813.
Copyright $\odot 2020$ by Thieme Medical Publishers, Inc., 333 Seventh Avenue, New York, NY 10001, USA. Tel: +1(212) 760-0888.
License terms

()ㅇㅇㅛ $\Theta$ 


\section{Patients and Methods}

This study was conducted with approval from the institutional ethics committee, in conformance with the Helsinki Declaration, and in strict adherence to the STROBE guidelines. All patients were provided written informed consent. All patients with lower limb lymphedema refractory to conventional compression therapy with elastic stockings who underwent LVA surgery between July 1, 2018 and October 30, 2018, in international lymphedema center in Hiroshima were included in the study. Thirteen patients with lymphedema in extremities were finally enrolled based on the following inclusion criteria: Campisi clinical stage 2 or 3 lymphedema ${ }^{4}$ and indocyanine green (ICG) lymphography findings compatible with a Yamamoto classification of 1 to $3 .^{5}$

Diagnostic lymphography was performed by injecting 0.1 to $0.2 \mathrm{~mL}$ of ICG dye (Diagnogreen 0.5\%; Daiichi Pharmaceuticals, Tokyo, Japan) subcutaneously into the first interdigital space and into the posterior lateral condylar region. The ICG images were acquired using a Photodynamic Eye system (Hamamatsu Photonics, Hamamatsu, Japan).

In all cases, the lymphedema was secondary to cervical, endometrial, ovarian, or another type of cancer. Each LVA site was planned precisely along a line traced by marking of the superficial lymphatic vessels which ICG lymphography indicated a linear pattern at first. After that, the site was decided at the place where venules for LVA were detected with color Doppler ultrasonography. Vein viewer and ultrasonography for lymphatic detection were not used in all cases. End-toend anastomoses were performed with lymphatics as the peripheral vessels and veins as the proximal vessels. All LVAs were performed under local anesthesia.

\section{Operating Surgeons}

The procedures on each leg were performed by two operating surgeons, one of whom was an expert with at least

\section{Line Production System (LPS)}
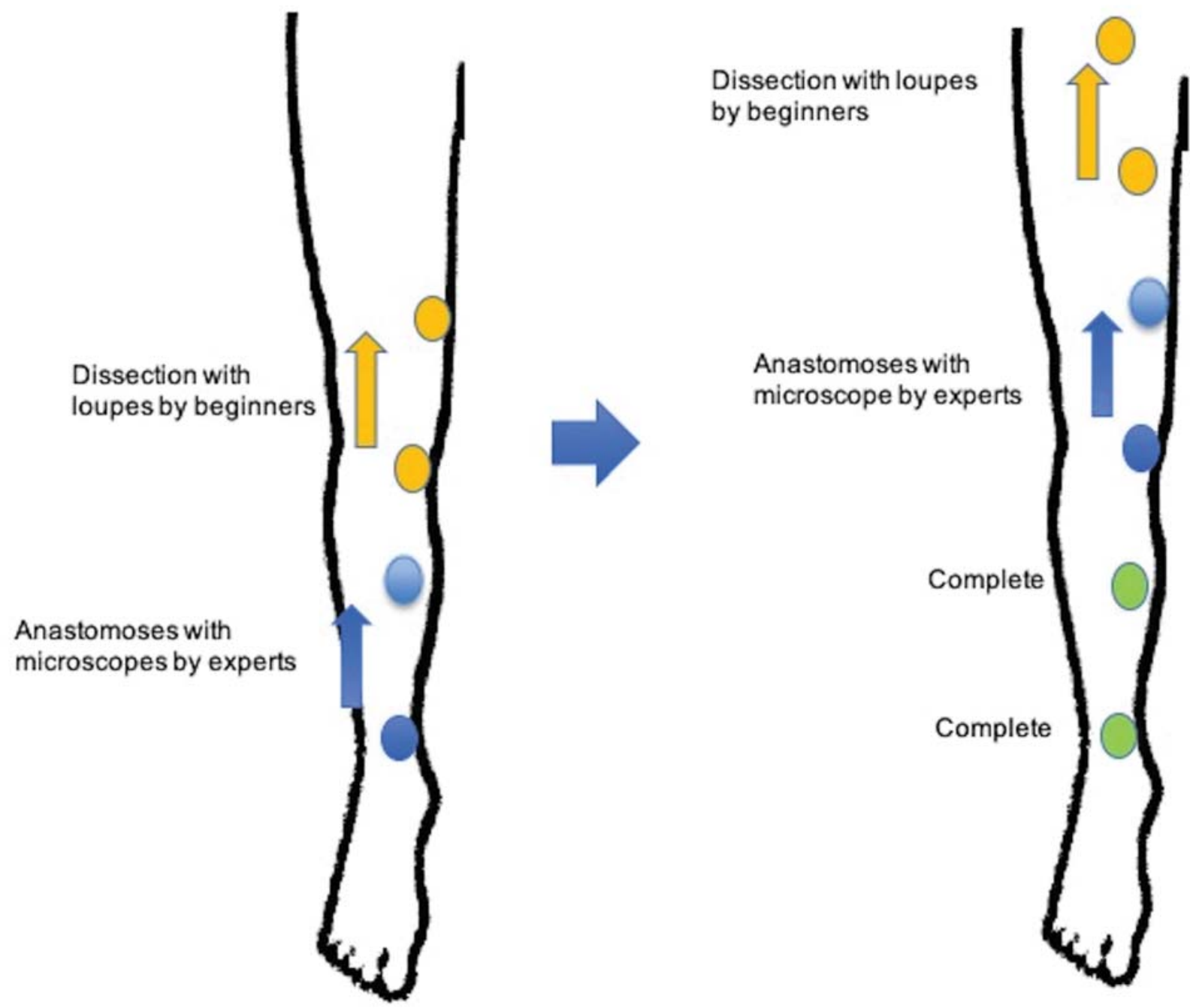

Fig. 1 Schema showing the line production system that can be used to perform multiple lymphaticovenular anastomoses. Using this system, a novice microsurgeon uses loupes to dissect and detect veins and lymphatics while an expert microsurgeon uses a microscope to perform the lymphaticovenular anastomoses. If necessary, the expert microsurgeon also dissects the veins and lymphatics. 
2 years of experience performing LVAs and the other a novice who had been performing LVAs for less than 6 months but had more than 2 months of experience in microsurgery before performing LVA and had successfully completed microsurgery training for LVA. ${ }^{6}$ The novice surgeons were instructed about how to dissect lymphatics, the morphological features of lymphatics, and how to discriminate lymphatics from nerves or fibrotic bundle through observing microsurgical images during LVA before their starting dissection under loupes at least three times. There was no assistant surgeon.

\section{Line Production System}

The roles are divided between a novice microsurgeon and an expert microsurgeon when using the LPS to perform multi- ple LVAs. The novice starts at the region around the knee far away from where the expert is workings so as not to interfere with the expert's LVA. The novice detects and dissects the lymphatics using loupes. 3-0 Nylon sutures are placed under the identified vein and lymphatic candidates act as markers. The novice repeats the same procedure on the legs toward the proximal region up to the inguinal region.

Meanwhile, the expert microsurgeon starts the LVA procedure from the ankle area. The entire procedure is performed under an operating microscope. On completing the LVAs at the peripheral region around the ankle, the expert moves proximally to the region already dissected by the novice surgeon. The expert confirms that the target lymphatics and veins have been correctly identified and performs the LVAs. If the novice cannot identify the lymphatics
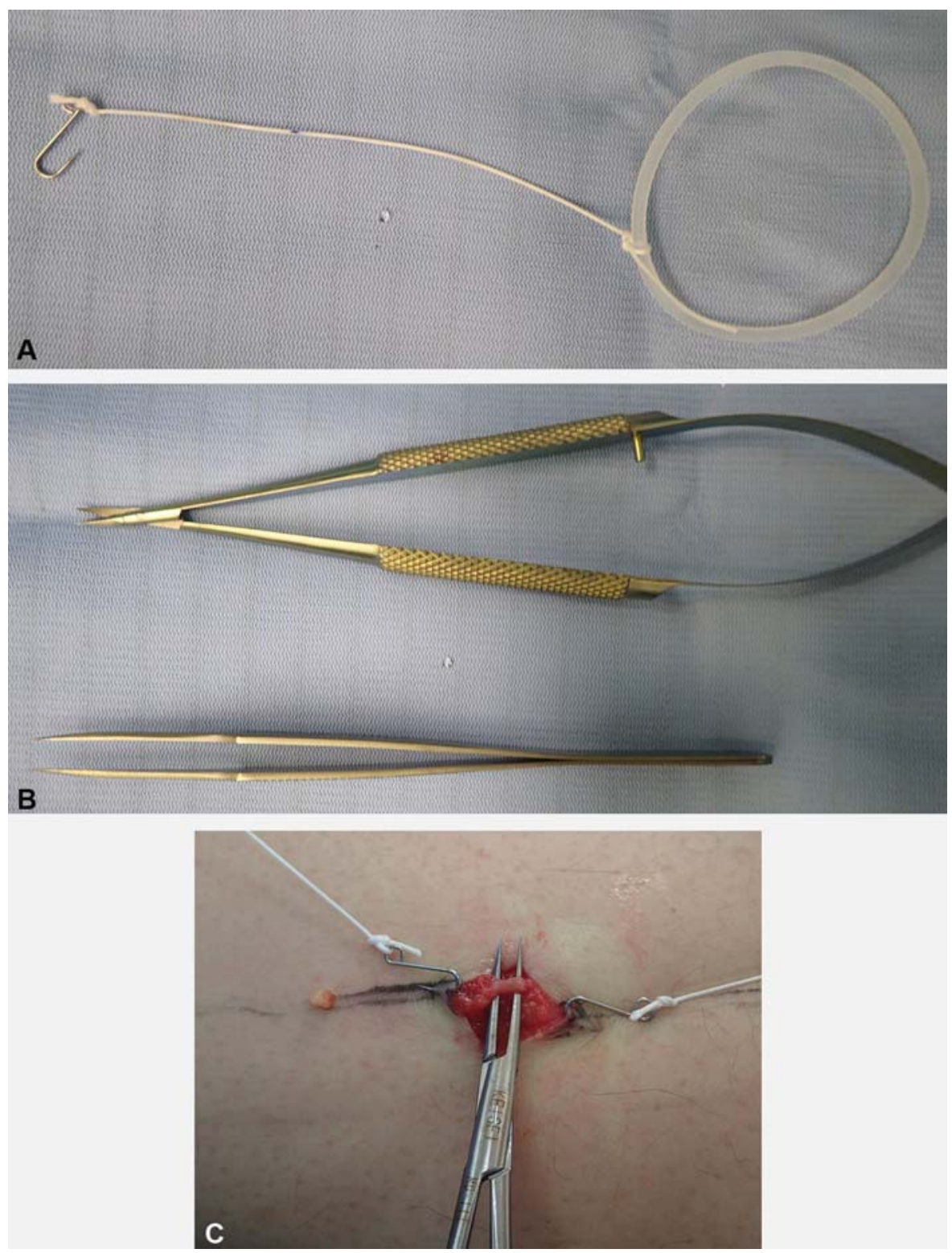

Fig. 2 (A) Using a retractor for LVA surgery (Kono Seisakusyo Co., Ltd., Ichikawa, Japan) is also helpful during dissection under loupes. (B). Using microscissors and forceps made of titanium (EMI Factory Co., Ltd., Nagano, Japan) is hel pful for carefully cutting the remaining dermis or selectively removing fat globules from the lymphatic vessel. (C) Blunt dissection is performed using a pair of micromosquito forceps with curved tips (Keisei Medical Industrial Co Ltd., Tokyo, Japan) to identify collecting lymphatics and veins in the subcutaneous fat layer. After detecting a lymphatic, the tips of the curved micromosquito forceps are passed beneath the vessel, taking care to avoid injury. LVA, lymphaticovenular anastomoses. 
or veins, the expert microsurgeon searches for these structures in the dissected tissue under a microscope. When the anastomosis is complete, the expert moves on to the next site already dissected by the novice (-Fig. 1).

\section{Dissection under Loupes}

The lymphatics are dissected using loupes (Univet, Rezzato, Italy) with $4 \times$ magnification. Local anesthesia is achieved by subdermal injection of a mixture of adrenalin $1 \%$ and lidocaine $2 \%$ (in a ratio of $1: 9$ ), which also minimizes the need for electrocautery. Next, a size 15 blade is used to make a $1.5-\mathrm{cm}$ skin incision to the deep dermis. A retractor for LVA surgery (Kono Seisakusho Co., Ltd., Ichikawa, Japan) is used for retraction ( $\mathbf{- F i g . ~ 2 A}$ ) and the remaining dermis is cut carefully using microscissors and forceps made of titanium (EMI Factory Co., Ltd., Nagano, Japan) (-Fig. 2B) to preserve any subdermal veins that could be anastomosed later. If the cutaneous vein is in the middle of the incision site and thereby hindering further dissection, it is clamped from one side (decided by the result of a milking test) and transected from the opposite side. Blunt dissection is performed using a pair of micromosquito forceps with curved tips (Keisei Medical Industrial Co Ltd., Tokyo, Japan) to identify collecting lymphatics and veins in the subcutaneous fat layer ( - Fig. 2C). The lymphatics are transparent threadlike structures arranged longitudinally in the subcutaneous adipose tissue and may be oriented with feeding capillary vessels running along the clear lymphatic vessel wall (-Fig. 3 ). In most cases, the diameter of a collecting lymphatic is in the range of 0.2 to $1.0 \mathrm{~mm}$. In patients with more advanced lymphedema, lymphatic wall may be fibrotic or sclerotic and may have a translucent appearance. Before starting the dissection, it is helpful to put a scale for reference in the field of vision, such as a background material (Keisei Medical Industrial Co., Ltd., Tokyo, Japan) that contains a $1 \times 1 \mathrm{~mm}^{2}$ pattern marked with a line $0.1-\mathrm{mm}$ wide to grasp a sense of the size while using loupes (- Figs. $3, \mathbf{4}$ ). After detecting the lymphatic, the tips of the curved micromosquito forceps are

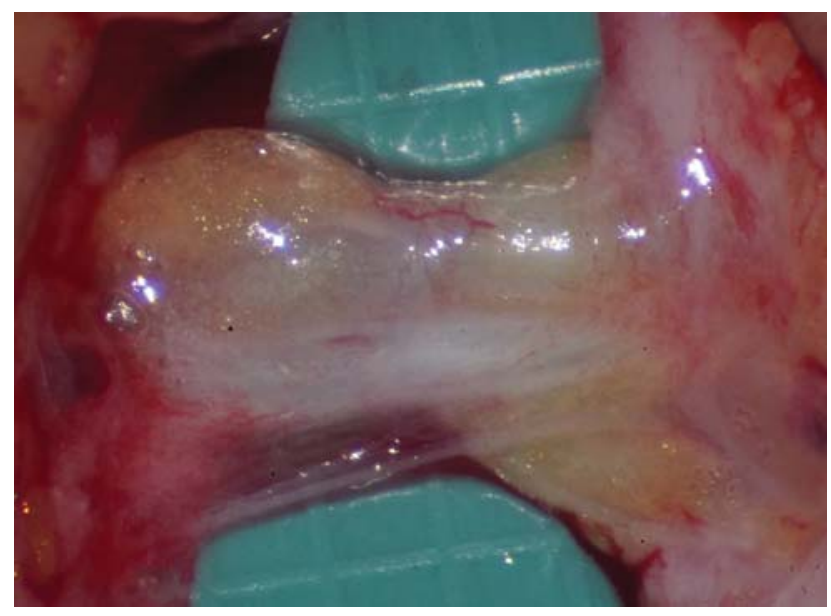

Fig. 3 The lymphatics are transparent threadlike structures arranged longitudinally in the subcutaneous adipose tissue and may be oriented with feeding capillary vessels running along the clear lymphatic vessel wall.

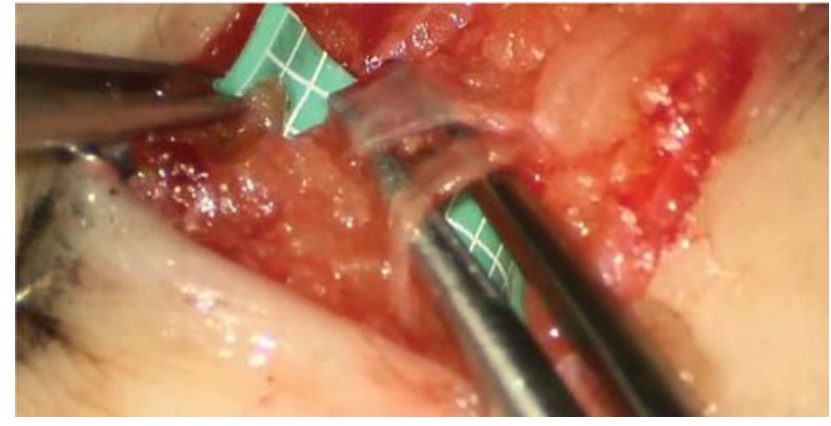

Fig. 4 The tips of a pair of curved micromosquito forceps are passed beneath the detected lymphatic taking care not to damage the vessel. A contrasting background material containing a grid pattern of known dimensions is helpful when separating lymphatics from fat tissue.

passed beneath the vessel, taking care to avoid injury (-Fig. 2C). The lymphatic beneath which the tips of the micromosquito forceps have been passed is then hooked upward with the surrounding fat tissue. Next, the tips of the micromosquito forceps are opened slightly, and a piece of the background material cut into the shape of a long triangle is inserted beneath the elevated lymphatic to create contrast. The background material is helpful when separating a lymphatic from fat tissue because of the clear contrast afforded (-Fig. 4). Microforceps and microscissors are used to selectively remove fat globules from the lymphatic vessel. The same procedure is performed to dissect a vein.

Finally, before handing over to the expert surgeon, the novice surgeon sprays papaverine hydrochloride solution (Papaverine Hydrochloride; Nichi-Iko Pharmaceutical Company, Limited, Toyama, Japan; $4 \mathrm{mg} / \mathrm{mL}$ ) diluted in $9 \mathrm{~mL}$ of saline over the exploration site while waiting for confirmation under the microscope and further skeletonization and anastomosis.

\section{Results}

Mean time for exploration under loupes was $25 \pm 7$ minutes; lymphatics were successfully found in 27 sites (90\%) of the 30 attempted with failure to identify lymphatics in three sites (10\%) and failure to identify veins in three sites (10\%); the average size of lymphatics was found to be $0.5 \pm 0.2 \mathrm{~mm}$. All results were confirmed under operating microscope with high magnification (up to $20 \times$ ) and a further attempt by an expert surgeon to find a lymphatic and a venule was performed in three incisions. No lymphatics could be found by the microscopes after loups exploration only in two sites ( $\mathbf{- T a b l e ~} \mathbf{1}$ ).

\section{Discussion}

The advantages of LPS is an increase in the number and quality of the LVAs, which leads to further improvement in lymphedema with fewer microscopes and microsurgeons and a shorter operating time. ${ }^{3}$

Using the LPS, it is not always necessary to completely identify and dissect lymphatics and veins at the stage of blunt dissection under loupes because further dissection and 
Table 1 All results were confirmed under operating microscope with high magnification (up to $20 \times$ ) and a further attempt by expert surgeon to find a lymphatic and a venule was performed in three incisions. No lymphatics could be found by the microscopes after loups exploration only in two sites.

\begin{tabular}{|c|c|c|c|c|c|c|c|}
\hline Patients & Sex & $\begin{array}{l}\text { Age } \\
\text { (year old) }\end{array}$ & $\begin{array}{l}\text { Sites of } \\
\text { exploration }\end{array}$ & $\begin{array}{l}\text { Dissection } \\
\text { time (min) }\end{array}$ & $\begin{array}{l}\text { Vein } \\
\text { dissection }\end{array}$ & $\begin{array}{l}\text { Lymphatic } \\
\text { dissection }\end{array}$ & $\begin{array}{l}\text { Lymphatic } \\
\text { size (mm) }\end{array}$ \\
\hline \multirow[t]{2}{*}{1} & \multirow[t]{2}{*}{$\mathrm{F}$} & \multirow[t]{2}{*}{45} & Lower leg & 20 & Success & Success & 0.6 \\
\hline & & & Upper thigh & 30 & Success & Success & 0.4 \\
\hline \multirow[t]{2}{*}{2} & \multirow[t]{2}{*}{$\mathrm{F}$} & \multirow[t]{2}{*}{52} & Dorsum foot & 18 & Success & Success & 0.5 \\
\hline & & & Below knee & 28 & Success & Success & 0.3 \\
\hline \multirow[t]{3}{*}{3} & \multirow[t]{3}{*}{$\mathrm{F}$} & \multirow[t]{3}{*}{48} & Below knee & 25 & Success & Success & 0.6 \\
\hline & & & Lower thigh & 25 & Success & Success & 0.4 \\
\hline & & & Upper thigh & 31 & Success & Success & 0.3 \\
\hline \multirow[t]{2}{*}{4} & \multirow[t]{2}{*}{$M$} & \multirow[t]{2}{*}{77} & Lower thigh & 30 & Success & Success & 0.3 \\
\hline & & & Upper thigh & 30 & Success & Failure & - \\
\hline \multirow[t]{2}{*}{5} & \multirow[t]{2}{*}{ M } & \multirow[t]{2}{*}{66} & Lower leg & 20 & Success & Success & 0.5 \\
\hline & & & Below knee & 23 & Success & Success & 0.3 \\
\hline \multirow[t]{3}{*}{6} & \multirow[t]{3}{*}{$\mathrm{F}$} & \multirow[t]{3}{*}{84} & Above wrist & 21 & Success & Success & 0.4 \\
\hline & & & Mid forearm & 27 & Success & Success & 0.5 \\
\hline & & & Lower arm & 32 & Failure & Success & 0.5 \\
\hline \multirow[t]{3}{*}{7} & \multirow[t]{3}{*}{$\mathrm{F}$} & \multirow[t]{3}{*}{60} & Above wrist & 19 & Success & Success & 0.4 \\
\hline & & & Mid forearm & 30 & Failure & Success & 0.3 \\
\hline & & & Lower arm & 26 & Success & Success & 0.3 \\
\hline \multirow[t]{2}{*}{8} & \multirow[t]{2}{*}{$M$} & \multirow[t]{2}{*}{51} & Dorsum foot & 19 & Success & Success & 0.5 \\
\hline & & & Lower thigh & 29 & Success & Success & 0.3 \\
\hline \multirow[t]{2}{*}{9} & \multirow[t]{2}{*}{ M } & \multirow[t]{2}{*}{67} & Lower leg & 20 & Success & Success & 0.6 \\
\hline & & & Lower thigh & 31 & Success & Failure & - \\
\hline \multirow[t]{2}{*}{10} & \multirow[t]{2}{*}{$\mathrm{F}$} & 77 & Dorsum foot & 20 & Success & Success & 0.7 \\
\hline & & & Lower leg & 28 & Success & Success & 0.4 \\
\hline 11 & $F$ & 81 & Dorsum foot & 25 & Success & Success & 0.6 \\
\hline & & & Lower leg & 27 & Success & Success & 0.5 \\
\hline 12 & $\mathrm{~F}$ & 46 & Dorsum foot & 22 & Success & Success & 0.4 \\
\hline & & & Lower leg & 30 & Success & Success & 0.4 \\
\hline 13 & $\bar{F}$ & 37 & Above wrist & 31 & Success & Failure & - \\
\hline & & & Mid forearm & 29 & Failure & Success & 0.5 \\
\hline & & & Upper arm & 32 & Success & Success & 0.3 \\
\hline Average & & & & $25 \pm 7$ & $\begin{array}{l}\text { Success rate } \\
90 \%\end{array}$ & $\begin{array}{l}\text { Success rate } \\
90 \%\end{array}$ & $0.5 \pm 0.2$ \\
\hline
\end{tabular}

identification can be performed under a microscope if identification is not complete under loupes. ${ }^{3}$ However, it is desirable to identify lymphatics and veins at the stage of blunt dissection under loupes because our LPS is a method devised to allow as many LVAs as possible to be performed in a limited amount of time. ${ }^{3}$

Lymphatics are transparent vessels but need to be distinguished from nerve and fibrous tissues visually for LVA if fibrosis and sclerosis have occurred as a result of lymphedema progression. ${ }^{7}$ We distinguish fibrotic and sclerotic lymphatic vessels from nerves by the node of Ranvier, which appears on nerves as a horizontal striped pattern. Further- more, a lymphatic can be visually distinguished from nerve fiber bundle tissue by the transparency at the center of the cord and the cylindrical shape of the lymphatic, which can be followed gradually as the dissection proceeds.

Lymphatics are easily overlooked because of their transparency when no fibrosis is present. Even a novice surgeon can discriminate lymphatics when armed with the above knowledge. However, it is assumed that a higher loupe magnification is necessary for accurate discrimination. On the other hand, veins are easily distinguished because they contain blood, and so can be detected at a lower loupe magnification. 
Dyes such as patent blue have been used to identify lymphatic vessels. ${ }^{8}$ Use of patent blue is likely to increase the identification rate even at lower magnification loupes but loupes with a higher magnification should still be used because we often encounter no staining with patent blue.

At the beginning of the dissection, it is difficult to grasp a sense of size while using loupes. Therefore, it is helpful to put a scale for reference in the field of vision, such as a background material that contains a $1 \times 1 \mathrm{~mm}^{2}$ pattern to search for the same size tissues as lymphatics (the diameter is $0.2-1.0 \mathrm{~mm}$ in most of the cases). The background material is also helpful to confirm the characteristics of lymphatics because of its clear contrast.

Discrimination of lymphatics is mainly performed morphologically or visually. Therefore, it is important to use loupes with high magnification. It is also important to seize the sense of size and to create fine contrast using background material.

\section{Conflict of Interest}

None declared.

\section{References}

1 Mihara M, Hara H, Tange S, et al. Multisite lymphaticovenular bypass using supermicrosurgery technique for lymphedema management in lower lymphedema cases. Plast Reconstr Surg 2016;138(01):262-272

2 Yamamoto T, Koshima I, Yoshimatsu H, Narushima M, Miahara M, Iida T. Simultaneous multi-site lymphaticovenular anastomoses for primary lower extremity and genital lymphoedema complicated with severe lymphorrhea. J Plast Reconstr Aesthet Surg 2011;64(06):812-815

3 Yoshida S, Koshima I, Imai H, et al. Line production system for multiple lymphaticovenular anastomoses. J Plast Reconstr Aesthet Surg 2019;72(08):1334-1339

4 Campisi C, Boccardo F. Microsurgical techniques for lymphedema treatment: derivative lymphatic-venous microsurgery. World J Surg 2004;28(06):609-613

5 Yamamoto T, Matsuda N, Doi K, et al. The earliest finding of indocyanine green lymphography in asymptomatic limbs of lower extremity lymphedema patients secondary to cancer treatment: the modified dermal backflow stage and concept of subclinical lymphedema. Plast Reconstr Surg 2011;128(04): 314e-321e

6 Chen WF, Eid A, Yamamoto T, Keith J, Nimmons GL, Lawrence WT A novel supermicrosurgery training model: the chicken thigh. J Plast Reconstr Aesthet Surg 2014;67(07):973-978

7 Mihara M, Hara H, Hayashi Y, et al. Pathological steps of cancerrelated lymphedema: histological changes in the collecting lymphatic vessels after lymphadenectomy. PLoS One 2012;7(07): e41126

8 Ayestaray B, Bekara F, Andreoletti JB. Patent blue-enhanced lymphaticovenular anastomosis. J Plast Reconstr Aesthet Surg 2013;66(03):382-389 